\title{
Morphology and Hemispheric and Gender difference of the Anterior Ascending Ramus and the Horizontal Ascending Ramus of the Lateral Sulcus
}

\section{Yu Wang}

Shandong University School of Medicine: Shandong University Cheeloo College of Medicine shuwei liu ( $\square$ liusw@sdu.edu.cn )

Shandong Medical Imaging Research Institute

\section{Fei fei Xu}

Shandong University School of Medicine: Shandong University Cheeloo College of Medicine

\section{Lan wei Hou}

Shandong University School of Medicine: Shandong University Cheeloo College of Medicine

\section{Wen Juan Zhou}

Shandong University School of Medicine: Shandong University Cheeloo College of Medicine

\section{Yu chun Tang}

Shandong University School of Medicine: Shandong University Cheeloo College of Medicine

\section{Research Article}

Keywords: Morphological pattern, Lateral sulcus, Broca's area, Asymmetry

Posted Date: February 24th, 2021

DOl: https://doi.org/10.21203/rs.3.rs-225084/v1

License: (1) This work is licensed under a Creative Commons Attribution 4.0 International License. Read Full License 


\section{Abstract}

Broca's area is composed of the pars opercularis (PO) and the pars triangularis (PTR) of the inferior frontal gyrus $₫$ which was separated by the anterior ascending ramus of lateral sulcus (aals) and the horizontal ascending ramus of the lateral sulcus (hals). The morphometry of these two sulci maybe have potential effects on the various functions of Broca's area. To explore the morphology variation, hemispheric and gender difference of these two sulci, so as to enable better understanding of their patterns and the functions of the Broca's area. BrainVISA was used to reconstruct and parameterize these two sulci with 3D MR images of 90 healthy right-handed subjects. The 3D anatomic morphology of these two sulci was presented using 4 sulcal parameters, including average depth (AD), average width (AW), top length (TL) and bottom length (BL). The aals could be identified in $98.89 \%$ of the hemispheres, while the hals could be identified in $98.33 \%$. The morphological patterns of these two sulci were categorized into four main types. There were no statistically significant interhemispheric and gender differences in the frequency of the morphological patterns. There was statistically significant interhemispheric difference in $B L$ of the aals and AW of the hals. Significant gender differences were found in the bilateral $A D$ of the aals and the BL and TL of the hals in right hemisphere. Our results will not only provide structural basis for the functional studies that related to Broca's area, but also be helpful for the precise positioning of special structures in neurosurgery.

\section{Introduction}

The Broca's area lying in the third frontal convolution and above the lateral sulcus, is primarily comprised

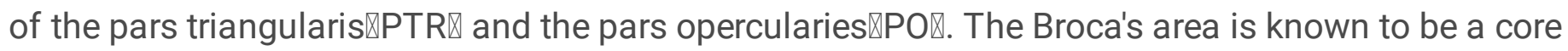
region for speech production. A wealth of neuroimaging analyses showed that activity in the pars opercularis and the pars triangularis increased during speech tasks(Heim et al. 2008; Amunts et al. 2004). And impairment to the posterior ventrolateral region of the left hemisphere could lead to dysfunction of speech production(Broca 1861). Generally, the typical clinical symptoms of Broca's aphasia are decreased speech fluency and mild-to-moderate impairment of speech comprehension(Pearce 2009). The area causing Broca's aphasia has been debated for more than a century. It is widely accepted that the damage limited to classical Broca's area probably involves parts of Broca's area and some other adjacent structures at present(Fridriksson et al. 2015).

The current research about Broca's area mainly focuses on the study of Occidental populations, but differences in genetics, culture and environmental exposures may give rise to differences in brain structure and function between the Oriental and Occidental populations(Lou et al. 2019; Han and Ma 2014). According to SBM analysis, compared to Westerners, the Chinese population had smaller structural measures in the frontal and parietal regions (Tang et al. 2018). In addition, the study of crosslanguage differences showed that the connections between the bilateral anterior temporal lobes and classical language areas are much stronger in a tonal (Chinese) language than in a nontonal (English) language, whereas the connections between the posterior temporal lobe and the inferior frontal lobe in left hemisphere is much stronger in a nontonal than in a tonal language during processing intelligible 
speech(Ge et al. 2015). It is obvious that cultural differences have been shown to affect linguistic functions of the brain(Xu et al. 2017). Therefore, it is necessary to utilize Chinese data to study Broca's area. Pars opercularis, namely area 44 , is invoved in the advanced control of the orofacial musculature(Petrides 2016). Functional imaging studies of normal human subjects indicate that Brodmann area (BA) 44 is involved in syntax processing, whereas BA 45 mainly contributes to semantic processing(Goucha and Friederici 2015). Evidence indicated that BA 45 was active in controlled processes at the word-level such as semantic judgment or categorization, lexical-semantic access, and aspects of sentence-level semantic plausibility(Westphal et al. 2016; Petrides 2013). The functions of the Broca's area have promoted the anatomical studies of the asymmetry of this region. The anterior ascending ramus of the lateral sulcus and the anterior horizontal ramus of the lateral sulcus are the natural boundaries of Broca. The morphology of these two sulci are complex and their morphological changes perhaps cause changes in volume and cortical surface area of Broca. However, there are few studies on the anterior ascending ramus of the lateral sulcus (aals) and the horizontal ascending ramus of the lateral sulcus (hals), especially in Chinese.

Sex differences in the brain structure have been reported, ranging from global differences to local differences in regional tissue volume and the size of substructure(Luders et al. 2013; Xu et al. 2000). Kurth $F$ (2017) found that the bilateral gray matter volume of BA 44 and BA 45 was significantly greater in females than in males, while the gender difference was not significant in BA 44/45 asymmetry(Kurth et al. 2017). Sulcal width and depth of men have been reported to change more rapidly, especially in the temproal collateral and cingulate sulci(Kochunov et al. 2005). However, there are few studies on gender differences of these two sulci.

In order to understand the influence of these two sulci on the structure and function of Broca's area, in this study, we used in vivo brain MRI images with large sample size, advanced brain imaging and brain structure analysis methods. The present investigation was to characterize the morphology of these two sulci, to explore interhemispheric and gender difference on various morphometric parameters of these two sulci. It is expected to provide a method for complex brain sulcus analysis, provide anatomical basis for the function and related studies of Broca 's area, and provide basic guidance for functional neuroimaging studies and neurosurgical operations in related brain areas.

\section{Materials And Methods}

\section{Subjects}

90 Chinese volunteers (mean age $17.30 \pm 1.58$ years, 50 males and 40 females) were recruited in the study. All subjects had no history of neurological and /or psychiatric illness, corresponding to Diagnostic and Statistical Manual of Mental Disorders (DSM-IV). All subjects were right-handed measured with the Edinburgh handedness inventory. The ethics approval was obtained from the ethics committee of Shandong University before the initiation of this study. All participants and their parents have given written informed consent. 


\section{MRI acquisition and processing}

High quality three-dimensional structure MR data was acquired using a 3.0T GE (General Electric, Milwaukee, USA) MRI Scanner with a standard eight-channel head coil. Acquisition parameters for T1weighted structural MRI scan were identical and as follows: TR=18 ms; TE $=10 \mathrm{~ms}$; voxel size $=0.47 \mathrm{~mm}$ $\times 0.47 \mathrm{~mm} \times 0.70 \mathrm{~mm} ; \mathrm{FOV}=24.0 \mathrm{~cm} \times 24.0 \mathrm{~cm}$; matrix size $=512 \times 512 ;$ flip angle $=10^{\circ}$; slice thickness $=$ $1.4 \mathrm{~mm}$; slice gap $=-0.7 \mathrm{~mm} ; \mathrm{NEX}=2$; total scan time $=12 \mathrm{~min}$. All images were scanned along a horizontal line through the anterior and posterior commissures.

\section{Image processing}

First, all MR images were transformed to the standard space of the MNI305 atlas in FreeSurfer software (http://surfer.nmr.mgh.harvard.edu/fswiki/) using linear registration. Then the cortical sulci of subjects were reconstructed and automatically identified through BrainVISA囚BV\software (http://brainvisa.info/). Particularly, cortical sulci were analyzed using the following steps: T1-weighted MRI import, bias correction, calculation of the mean whole brain mask, mesh the cerebral hemispheres, removal of nonbrain tissue and segmentation of brain tissues into white/gray matter(W/GM) and cerebrospinal fluid (CSF), reconstruction of white/gray matter mesh , sulci recognition and automated labeling of sulci (Liu et al. 2010) (Fig .1). The labeling was firstly performed automatically $\bigotimes$ then the result was checked visually as well as corrected manually if mislabeled sulci were found. Each step can be visually checked by an experienced neuroanatomist. For manually labeled MRI sections, all images were pre-processed by FreeSurfer firstly. The sections were taken at $1.4 \mathrm{~mm}$ intervals. Using ITK-SNAP (http://www.itksnap.org/pmwiki/pmwiki.php), the manual annotation of the aals and hals was mainly completed in the sagittal section, while the results were corrected in the coronal section and transverse section. Moreover, the results of 3D reconstruction were compared with the result of BrainVISA to assist correction of the boundary of sulci.

\section{Computation of sulci parameters}

Measurements of sulcal length, sulcal width, and sulcal depth require the RIC tools for BrainVISA (http://ric.uthscsa.edu/personalpages/petr/). The average sulcal width (AW) for an individual sulcal structure was defined as an average 3D distance between opposing gyral banks along the normal projections to the medial sulcal mesh(Kochunov et al. 2005) (Fig.2). The average sulcal depth (AD) was calculated as the average Euclidean distance between the points along the deepest edge of the sulcal skeleton surface and the nearest points on the outer edge of the sulcal ribbon. The sulcal length consist of top length (TL) and bottom length (BL). The top length was defined as the length of the top edge of the sulcus. The bottom length was defined as the length of the ridge at the base of the sulcus (Kochunov et al. 2008; Kochunov et al. 2005)(Fig.3).

\section{Statistical analysis}


The chi-squared test of independence was conducted to investigate the significance of interhemispheric and gender differences in the frequency with which the morphological patterns of Type I, Type II, Type III and Type $\varangle$. The statistical analysis of interhemispheric and gender differences of sulci parameter value were examined using one of two approaches. Independent-samples t-test was used to analyses sulci parameter values which satisfied the parametric test. Mann-Whitney test was used to examine sulci parameter values which satisfied the nonparametric tests. $p<0.05$ was considered as statistically significant. The statistical analysis was conducted by the statistical software package SPSS (IBM SPSS, version 25).

\section{Results}

\section{Morphology of the aals and the hals}

The aals could be observed in $98.89 \%$ of subjects ( $98.89 \%$ of left hemispheres and right hemispheres). And the hals could be observed in $98.33 \%$ of subjects ( $97.78 \%$ of left hemispheres and $98.89 \%$ of right hemispheres). The morphological patterns of these two sulci could be categorized into four main types (Fig .4), the frequencies of which are presented in Table 1. Type $\nabla$ could be identified in $55.56 \%$ of subjects ( $47.78 \%$ of left hemispheres and $63.33 \%$ of right hemispheres). The characteristics of this type was that the aals is clearly separated from the hals, forming the shape of the letter $\mathrm{U}$ (Fig. 4 a b). In 15 (six left, nine right) of these hemispheres, showed that the aals and the hals formed the shape of the letter $U$

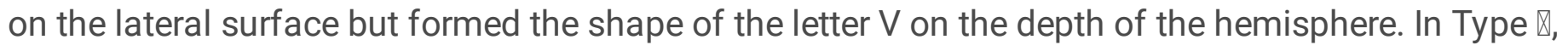
observed in $13.33 \%$ of cases ( $16.67 \%$ of left hemispheres and $10 \%$ of right hemispheres), the aals and the hals sprang from a common point, forming the shape of the letter $\mathrm{V}$ (Fig. $4 \mathrm{~cd}$ ). There are two cases in left hemisphere that the aals and the hals formed the shape of the letter $V$ on the lateral surface but

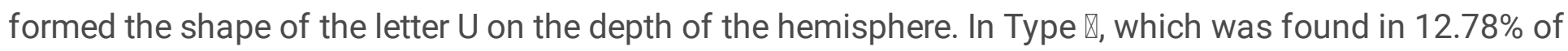
cases (13.33\% of left hemispheres and $12.22 \%$ of right hemispheres), the aals shares a common stem with the hals, forming the shape of the letter $\mathrm{Y}$ (Fig. $4 \mathrm{e}$ f). There was a third anterior ramus of the lateral fissure between the aals and the hals in Type $\otimes(F i g .4 \mathrm{~g} \mathrm{~h}$ ). This type found in $7.78 \%$ of cases. Additional morphological patterns were identified with less frequency (Fig.5): 1) The lack of the aals was observed in two $(2.22 \%)$ of the left and one ( $1.11 \%$ ) of the right hemispheres (Fig. 5 a b). 2 ) In $1.11 \%$ of cases ( $1.11 \%$ of left hemispheres and $1.11 \%$ of right hemispheres), the hals was absent (Fig 5. c d). 3) The aals was observed to bifurcate at its anterior end that was found in four $(4.44 \%)$ of the left and one $(1.11 \%)$ of the right hemispheres (Fig.5 e f) .4) The hals was observed to bifurcate at its anterior end that was found in six $(6.67 \%)$ of the left and three $(3.33 \%)$ of the right hemispheres (Fig. $5 \mathrm{~g} \mathrm{~h}$ ).

\section{Interhemispheric Differences}

There was statistically significant difference $\left(\chi^{2}=4.410, p<0.05\right)$ between the left and right hemispheres in Type I. However, this was no longer significant when a more conservative $p$ value was used in a continuity correction, which is required for two-by-two contingency tables. In Type II, Type III and Type $₫$, no 
statistically significant difference was found between the left and right hemispheres for any of these comparisons. The results were shown in Table 1.

The results of interhemispheric differences about sulcal parameters were shown in Table 2,3. There was statistically significant interhemispheric difference in $B L$ of the aals $(U=2923.000, p<0.05)$.

Interhemispheric difference was statistically significant in AW of the hals $(U=2818.000, p<0.05)$. There was no statistically significant interhemispheric difference in AW of the aals $(U=2676.000, p=0.608)$. Neither the aals nor the hals were statistically interhemispheric difference in TL (all $p>0.05$ ). The interhemispheric difference was no statistically significant in $B L$ of the hals $(U=3120.000, p=0.849)$. The $A D$ of the aals and the hals were no statistically interhemispheric difference (all $p>0.05$ ).

\section{Gender Differences}

For each comparison, there was no statistically significant gender difference. The results were presented in Table 4. The results of gender differences about sulcal parameters were shown in Table 5,6. There were significant gender differences in bilateral AD of the anterior ascending ramus of the lateral sulcus (all $p<$ 0.05). Moreover, in right hemisphere, gender difference was significant $(U=424.000, p=0.008)$ in $T L$ of the hals. There was significant gender difference in $\mathrm{BL}$ of the hals in right hemisphere $(\mathrm{t}=2.733, p=0.008)$. Whether it's in the aals or the hals, no significant differences on gender were observed for AW (all $p>$ 0.05). No significant gender differences were found in bilateral TL of the aals (all $p>0.05$ ). And in left hemisphere, there were no significant gender differences in $T L$ of the hals $(U=782.00, p=0.220)$. Bilateral $B L$ of the aals did approach significance on gender, while there was no significant gender difference of the $B L$ of the hals in left hemisphere. No significant gender differences were observed in bilateral $A D$ of the hals (all $p>0.05$ ). Analysis of the MRI Sections

The atlas which shown in supplementary materials presented a series of coronal, transverse, and sagittal sections from MRI transformed into the standard space of the MNI305. The four typical types of transverse section had following rules. The aals began to appear above the AC-PC level. Subsequently, the hals began to appear. The aals disappeared before the hals. When the aals and the hals appeared in

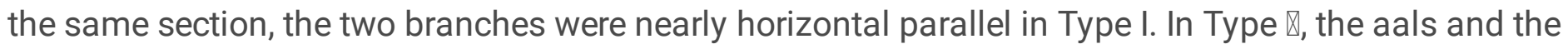
hals converged at an angle near the inner side of the brain, and the hals also gradually disappeared on the outer side of the brain after the aals disappeared. Similarly, the aals and the hals converged at an

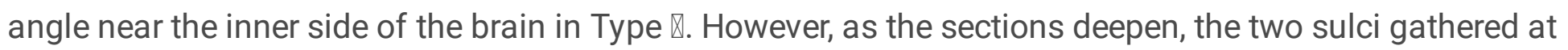
a sulcus. The third branch of the lateral sulcus occurred between the aals and the hals, and when the

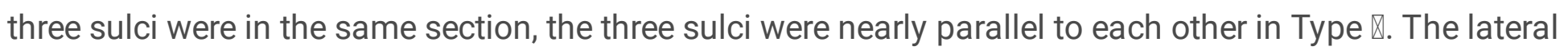
side of the brain from anterior to posterior was the hals, the third branch of the lateral fissure, the aals. When the two sulci were on the same plane, the two sulci also nearly horizontal paralleled. Four typical types can be distinguished by the sagittal plane, as shown in the supplementary material. The four typical types of consecutive coronal sections had following rules. When two branches appeared at the

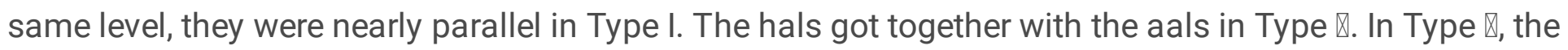

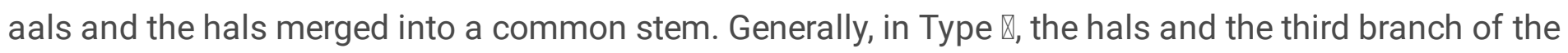


lateral fissure were nearly parallel in the same plane. When the hals disappeared, the aals appeared and was nearly parallel to the third branch of the lateral sulcus. The primary results of MRI sections were shown in Fig. 6-9. The consecutive transverse and coronal section of the atypical type had great variation and had not been analyzed in detail. The atypical type can be distinguished by the sagittal section.

\section{Discussion}

The present study determined the morphological variability of the anterior ascending ramus and the horizontal ascending ramus of the lateral sulcus. In our study, the morphological patterns of these two sulci were classified into typical and atypical types. The sulcal parameters were used to analyze hemispheric and gender differences of these two sulci.

The aals and the hals are two defining sulci of the posterior ventrolateral frontal cortex of the human brain. These two sulci are well distinguished from the other adjacent sulcus considering the characteristics of the cortical surface and the depth of these two sulci. The aals could be observed in $98.89 \%$ of the hemisphere, the hals could be observed in $98.33 \%$ of the hemisphere in our study. The results are slightly different from other studies(Sprung-Much and Petrides 2018; Powell et al. 2012; Sprung-Much and Petrides 2020; Keller et al. 2007). The discrepancy maybe attributed to the great heterogeneity in the brain samples and the differences of sample sizes. The typical morphological patterns of these two sulci were classified into four types. Type $\otimes$ was the typical morphology, the aals was clearly separated from the hals. A number of studies has been demonstrated(Keller et al. 2007). Interestingly, in our study, some cases in Type $\otimes$ showed that the aals and the hals formed the shape of the letter $\mathrm{U}$ on the lateral surface but formed the shape of the letter $\mathrm{V}$ on the depth of the hemisphere. The literature on this finding is still scarce. This may be because it is difficult to study these features in 3D data sets or because of the inconvenience of processing large amounts of data. The aals and the hals formed the shape of the letter $\vee$ in Type $\otimes$. In Type $\otimes$, the aals shared a common trunk with the hals. The common trunk was either superficial or extended to the level of the insula. This founding was line with earlier studies which studied morphology and spatial probability maps of the horizontal ascending ramus of the lateral fissure. There were cases that a third anterior ramus of the lateral sulcus lied between the aals and the hals. This type observed in $16 \%$ of hemispheres in study of Sprung-Much(Sprung-Much and Petrides 2020). Unlike Sprung-Much's results, the present study only found $7.78 \%$ cases. We speculate that it may be ascribed to the potential differences between Chinese and Western brains. In the present investigation, the aals or the hals was observed to bifurcate at its anterior end. The results of SprungMuch's study only showed that the hals was bifurcated at its anterior end. This may be caused by our inconsistent classification standards, or it may be due to our larger sample size. Overall, the morphology of these two sulci is complex and characterized by a high inter-subject variability. The results presented with analysis of the MRI Sections provided a detail way to distinguish the aals and the hals.

In our study, interhemispheric differences in the frequency of the morphological patterns of Type I, Type II, Type III, and Type $₫$ were analyzed. As shown in Table 1, none of the comparisons were significant. The results were similar to those described by Sprung-Much et al (2020). Although there is no hemispheric 
difference in the morphological types of the two sulci, there are hemispheric differences in the measured values of these two sulci. The sulcal measured values can reflect the quantitative information of sulci. There was hemispheric difference in BL of the aals in our study, which may account for a higher g-SIs of the right hemisphere. Global sulcal indices (g-Sls) reflected the complexity of sulcal folds. Liu et al (2010), which used automated methods to explore global sulcal indices (g-Sls) of both cerebral hemispheres in elderly, found a higher g-SI of the right hemisphere than that of the left hemisphere(Liu et al. 2010). Evidence showed that the lengths of primary sulci could reflect the local pattern of the cerebral gyrification(Imai et al. 2011), the hemispheric difference in BL of the aals may suggests hemispheric asymmetry of gyrus folding. Radiologists often use sulcal width as a measure of cerebral health in clinical practice(Hamelin et al. 2015). In the course of mild cognitive impairment and dementia, visual assessment of regional "widening" of cortical sulci (specifically in the hippocampal, enthorhinal, and medial temporal cortices) are associated with neurocognitive decline(Bastos Leite et al. 2004). The interhemispheric difference in AW of the hals was significant, we raised the possibility that it might be potentially related to language lateralization. With regard to the relation between the interhemispheric difference of AW of the hals and language lateralization, it merits further investigation by functional imaging methods.

Our finding shows that sex difference of the four typical morphological patterns of the aals and the hals was no statistically significant difference. The literature on sex difference exploring morphological patterns of the aals and the hals has been scare, especially in Chinese population. This may be caused by limited research methods and insufficient sample size. The AD of the anterior ascending ramus of the lateral sulcus shows significantly gender difference in left hemisphere, as well as in right hemisphere. Sulcal depth of all sulci more strongly linked the volumes of adjacent gyri than global volumes. The difference of $A D$ of the anterior ascending ramus of the lateral sulcus may be related to the asymmetry of the adjacent gyri, it can be indirectly inferred that there may be sex differences between gyri in Broca' $s$ area. These results confirm women's advantages in relation to language, particularly in terms of fluency and verbal memory tasks. The results support previous studies reporting sex differences in brain structure and function(Cosgrove et al. 2007; Frere et al. 2020; Wierenga et al. 2018). Our study found that female was characterized with longer $T L$ and $B L$ of the horizontal ascending ramus of the lateral sulcus in the right hemisphere, is in accordance with which found women had greater gyrification than men of 20-30 years of age (Luders et al. 2004). The g-SI increase with an increase in number and/or area of sulcal folds. The TL and BL were closely related to the change of $\mathrm{g}-\mathrm{SI}$.

\section{Limitation And Future Directions}

Several potential limitations exist in our study. The sample size is a limitation of this study. The amount of data is large compared to other studies, but the analysis of neuroimaging often requires a larger amount of data. Another limitation of our study is that the results should be verified by the multiple methods. Although the accuracy of the results is analyzed by two methods of 3D reconstruction and section analysis, but we should use the multimodal method to better verify the results. We will increase the amount of data and use the multimodal method to perfect our results in next step. 
In conclusion, the present study provides a detail description of the morphology of the anterior ascending ramus of the lateral sulcus and the horizontal ascending of the lateral sulcus. The morphology of these two sulci presented here can aid on improving sulcal identification, meantime, the present study reports a detailed analysis of difference of sulci quantitative information. The study sheds light for identifying these two sulci, it also plays a guiding role in the selection of surgical approach in the treatment of this area. Moreover, the results presented here provide anatomic basis for the exploration of functions of the Broca's area.

\section{Declarations}

\section{Funding}

This work was supported by the National Natural Science Foundation of China (NO 81371533, 2017cxGC1501). Shuwei Liu approved to summit the manuscript.

\section{Author contribution}

Guarantors of integrity of entire study, Shuwei Liu, Yuchun Tang; manuscript drafting or manuscript revision for important intellectual content, all authors; study concepts/study design or data acquisition or data analysis/interpretation, Yu Wang, Zhuoran Li, Feifei Xu; approval of final version of submitted manuscript, all authors; agrees to ensure any questions related to the work are appropriately resolved, all authors;literature research, Yuchun Tang, Yu Wang; experimental studies, Qi Zhang, Yu Wang;and manuscript editing, Shuwei Liu, Yu Wang, Zhuoran Li, Feifei Xu, Lanwei Hou.

Ethical standards The authors declare that they have no competing financial or non-financial interests. All research was conducted in compliance with ethical standards.

Conflicts of interest We declare that we have no conflict of interest.

\section{Ethical approval}

All procedures performed in studies involving human participants were in accordance with the ethical standards of the institutional .

\section{Acknowledgements}

This work was supported by the National Natural Science Foundation of China (NO 81371533, 2017cxGC1501). We declare that we have no conflict of interest. Shuwei Liu approved to summit the manuscript.

\section{References}


Amunts K, Weiss PH, Mohlberg H, Pieperhoff P, Eickhoff S, Gurd JM, Marshall JC, Shah NJ, Fink GR, Zilles $K$ (2004) Analysis of neural mechanisms underlying verbal fluency in cytoarchitectonically defined stereotaxic space--the roles of Brodmann areas 44 and 45. Neuroimage 22 (1):42-56. doi:10.1016/j.neuroimage.2003.12.031

Bastos Leite AJ, Scheltens P, Barkhof F (2004) Pathological aging of the brain: an overview. Top Magn Reson Imaging 15 (6):369-389. doi:10.1097/01.rmr.0000168070.90113.dc

Broca (1861) Nouvelle observation d'aphémie produite par une lésion de la moitié postérieure des deuxième et troisième circonvolutions frontales. Bull Soc Anatom Paris. 36:398-407

Cosgrove KP, Mazure CM, Staley JK (2007) Evolving knowledge of sex differences in brain structure, function, and chemistry. Biol Psychiatry 62 (8):847-855. doi:10.1016/j.biopsych.2007.03.001

Frere PB, Vetter NC, Artiges E, Filippi I, Miranda R, Vulser H, Paillere-Martinot ML, Ziesch V, Conrod P, Cattrell A, Walter H, Gallinat J, Bromberg U, Jurk S, Menningen E, Frouin V, Papadopoulos Orfanos D, Stringaris A, Penttila J, van Noort B, Grimmer Y, Schumann G, Smolka MN, Martinot JL, Lemaitre H, Imagen c (2020) Sex effects on structural maturation of the limbic system and outcomes on emotional regulation during adolescence. Neuroimage 210:116441. doi:10.1016/j.neuroimage.2019.116441

Fridriksson J, Fillmore P, Guo D, Rorden C (2015) Chronic Broca's Aphasia Is Caused by Damage to Broca's and Wernicke's Areas. Cereb Cortex 25 (12):4689-4696. doi:10.1093/cercor/bhu152

Ge J, Peng G, Lyu B, Wang Y, Zhuo Y, Niu Z, Tan LH, Leff AP, Gao JH (2015) Cross-language differences in the brain network subserving intelligible speech. Proc Natl Acad Sci U S A 112 (10):2972-2977. doi:10.1073/pnas.1416000112

Goucha T, Friederici AD (2015) The language skeleton after dissecting meaning: A functional segregation within Broca's Area. Neuroimage 114:294-302. doi:10.1016/j.neuroimage.2015.04.011

Hamelin L, Bertoux M, Bottlaender M, Corne H, Lagarde J, Hahn V, Mangin JF, Dubois B, Chupin M, de Souza LC, Colliot O, Sarazin M (2015) Sulcal morphology as a new imaging marker for the diagnosis of early onset Alzheimer's disease. Neurobiol Aging 36 (11):2932-2939.

doi:10.1016/j.neurobiolaging.2015.04.019

Han S, Ma Y (2014) Cultural differences in human brain activity: a quantitative meta-analysis. Neuroimage 99:293-300. doi:10.1016/j.neuroimage.2014.05.062

Heim S, Eickhoff SB, Amunts K (2008) Specialisation in Broca's region for semantic, phonological, and syntactic fluency? Neuroimage 40 (3):1362-1368. doi:10.1016/j.neuroimage.2008.01.009

Imai N, Sawada K, Fukunishi K, Sakata-Haga H, Fukui Y (2011) Sexual dimorphism of sulcal length asymmetry in the cerebrum of adult cynomolgus monkeys (Macaca fascicularis). Congenit Anom (Kyoto) 51 (4):161-166. doi:10.1111/j.1741-4520.2011.00330.x 
Keller SS, Highley JR, Garcia-Finana M, Sluming V, Rezaie R, Roberts N (2007) Sulcal variability, stereological measurement and asymmetry of Broca's area on MR images. J Anat 211 (4):534-555. doi:10.1111/j.1469-7580.2007.00793.x

Kochunov P, Mangin JF, Coyle T, Lancaster J, Thompson P, Riviere D, Cointepas Y, Regis J, Schlosser A, Royall DR, Zilles K, Mazziotta J, Toga A, Fox PT (2005) Age-related morphology trends of cortical sulci. Hum Brain Mapp 26 (3):210-220. doi:10.1002/hbm.20198

Kochunov P, Thompson PM, Coyle TR, Lancaster JL, Kochunov V, Royall D, Mangin JF, Riviere D, Fox PT (2008) Relationship among neuroimaging indices of cerebral health during normal aging. Hum Brain Mapp 29 (1):36-45. doi:10.1002/hbm.20369

Kurth F, Jancke L, Luders E (2017) Sexual dimorphism of Broca's region: More gray matter in female brains in Brodmann areas 44 and 45. J Neurosci Res 95 (1-2):626-632. doi:10.1002/jnr.23898

Liu T, Wen W, Zhu W, Trollor J, Reppermund S, Crawford J, Jin JS, Luo S, Brodaty H, Sachdev P (2010) The effects of age and sex on cortical sulci in the elderly. Neuroimage 51 (1):19-27. doi:10.1016/j.neuroimage.2010.02.016

Lou Y, Zhao L, Yu S, Sun B, Hou Z, Zhang Z, Tang Y, Liu S (2019) Brain asymmetry differences between Chinese and Caucasian populations: a surface-based morphometric comparison study. Brain Imaging Behav. doi:10.1007/s11682-019-00184-7

Luders E, Gaser C, Jancke L, Schlaug G (2004) A voxel-based approach to gray matter asymmetries. Neuroimage 22 (2):656-664. doi:10.1016/j.neuroimage.2004.01.032

Luders E, Kurth F, Toga AW, Narr KL, Gaser C (2013) Meditation effects within the hippocampal complex revealed by voxel-based morphometry and cytoarchitectonic probabilistic mapping. Front Psychol 4:398. doi:10.3389/fpsyg.2013.00398

Pearce JMS (2009) Broca's Aphasiacs. European Neurology 61 (3):183-189. doi:10.1159/000189272

Petrides M (2014) Neuroanatomy of language regions of the human brain. Chicago:Academic Press.

Petrides M (2016) The ventrolateral frontal region. In: Neurobiology of Language. London:Academic Press,pp 25-33 Powell JL, Kemp GJ, Roberts N, Garcia-Finana M (2012) Sulcal morphology and volume of Broca's area linked to handedness and sex. Brain Lang 121 (3):206-218.

doi:10.1016/j.bandl.2012.03.003

Sprung-Much T, Petrides M (2018) Morphological patterns and spatial probability maps of two defining sulci of the posterior ventrolateral frontal cortex of the human brain: the sulcus diagonalis and the anterior ascending ramus of the lateral fissure. Brain Struct Funct 223 (9):4125-4152.

doi:10.1007/s00429-018-1733-y 
Sprung-Much T, Petrides M (2020) Morphology and Spatial Probability Maps of the Horizontal Ascending Ramus of the Lateral Fissure. Cereb Cortex 30 (3):1586-1602. doi:10.1093/cercor/bhz189

Tang Y, Zhao L, Lou Y, Shi Y, Fang R, Lin X, Liu S, Toga A (2018) Brain structure differences between Chinese and Caucasian cohorts: A comprehensive morphometry study. Hum Brain Mapp 39 (5):21472155. doi:10.1002/hbm.23994

Westphal AJ, Reggente N, Ito KL, Rissman J (2016) Shared and distinct contributions of rostrolateral prefrontal cortex to analogical reasoning and episodic memory retrieval. Hum Brain Mapp 37 (3):896-912. doi:10.1002/hbm.23074

Wierenga LM, Sexton JA, Laake P, Giedd JN, Tamnes CK, Pediatric Imaging N, Genetics S (2018) A Key Characteristic of Sex Differences in the Developing Brain: Greater Variability in Brain Structure of Boys than Girls. Cereb Cortex 28 (8):2741-2751. doi:10.1093/cercor/bhx154

Xu J, Kobayashi S, Yamaguchi S, lijima K, Okada K, Yamashita K (2000) Gender effects on age-related changes in brain structure. AJNR Am J Neuroradiol 21 (1):112-118

Xu M, Baldauf D, Chang CQ, Desimone R, Tan LH (2017) Distinct distributed patterns of neural activity are associated with two languages in the bilingual brain. Sci Adv 3 (7):e1603309.

doi:10.1126/sciadv.1603309

\section{Tables}


Table 1

Frequency of morphological patterns of the aals and the hals in the left and right hemispheres of the human brain

\begin{tabular}{|c|c|c|c|c|c|c|c|c|}
\hline & $\begin{array}{l}\text { Total } \\
\text { no. LH }\end{array}$ & $\begin{array}{l}\% 90 \\
\text { LH }\end{array}$ & $\begin{array}{l}\text { Total } \\
\text { no. } \\
\text { RH }\end{array}$ & $\begin{array}{l}\% 90 \\
\mathrm{RH}\end{array}$ & $\begin{array}{l}\text { Total } \\
\text { no. LH } \\
+ \text { RH }\end{array}$ & $\begin{array}{l}\% 180 \\
\mathrm{LH}+ \\
\mathrm{RH}\end{array}$ & $\begin{array}{l}\text { Pearson Chi- } \\
\text { square }\end{array}$ & $P$ value \\
\hline Type I & 43 & 47.78 & 57 & 63.33 & 100 & 55.56 & $4.410(3.803)$ & $0.036(0.051)$ \\
\hline Type II & 15 & 16.67 & 9 & 10.00 & 24 & 13.33 & $1.731(1.202)$ & $0.188(0.273)$ \\
\hline Type III & 12 & 13.33 & 11 & 12.22 & 23 & 12.78 & $0.050(0.000)$ & $0.823(1.000)$ \\
\hline Type $\otimes$ & 7 & 7.78 & 7 & 7.78 & 14 & 7.78 & 0.000 & 1 \\
\hline Only aals & 1 & 1.11 & 1 & 1.11 & 2 & 1.11 & - & - \\
\hline Only hals & 2 & 2.22 & 1 & 1.11 & 3 & 1.67 & - & - \\
\hline $\begin{array}{l}\text { Bifurcated } \\
\text { aals }\end{array}$ & 4 & 4.44 & 1 & 1.11 & 5 & 2.78 & - & - \\
\hline $\begin{array}{l}\text { Bifurcated } \\
\text { hals }\end{array}$ & 6 & 6.67 & 3 & 3.33 & 9 & 5 & - & - \\
\hline
\end{tabular}

Table 2

Inter-hemispheric differences of sulcal parameters of the aals.

\begin{tabular}{|c|c|c|c|c|}
\hline Subgroup & Side & Sulcal parameter & U or t value & $P$ value \\
\hline \multirow[t]{2}{*}{$\mathrm{AW}(\mathrm{mm})$} & Left & $3.735 \pm 1.085$ & \multirow[t]{2}{*}{2676.000 * } & \multirow[t]{2}{*}{0.608} \\
\hline & Right & $3.644 \pm 0.912$ & & \\
\hline \multirow[t]{2}{*}{$\mathrm{TL}(\mathrm{mm})$} & Left & $19.996 \pm 7.288$ & \multirow[t]{2}{*}{-0.661} & \multirow[t]{2}{*}{0.510} \\
\hline & Right & $20.676 \pm 6.330$ & & \\
\hline \multirow[t]{2}{*}{$\mathrm{BL}(\mathrm{mm})$} & Left & $22.816 \pm 5.632$ & \multirow[t]{2}{*}{2923.00 * } & \multirow[t]{2}{*}{$0.005^{\star \star}$} \\
\hline & Right & $25.294 \pm 6.833$ & & \\
\hline \multirow[t]{2}{*}{$\mathrm{AD}(\mathrm{mm})$} & Left & $11.748 \pm 3.115$ & \multirow[t]{2}{*}{-0.066} & \multirow[t]{2}{*}{0.947} \\
\hline & Right & $11.778 \pm 2.981$ & & \\
\hline
\end{tabular}


Table 3

Inter-hemispheric differences of sulcal parameters of the hals.

\begin{tabular}{|c|c|c|c|c|}
\hline Subgroup & Side & Sulcal parameters & U or t value & $P$ value \\
\hline \multirow[t]{2}{*}{$\mathrm{AW}(\mathrm{mm})$} & Left & $3.516 \pm 0.171$ & \multirow[t]{2}{*}{2818.000 * } & \multirow[t]{2}{*}{$0.047^{\star \star}$} \\
\hline & Right & $3.607 \pm 0.127$ & & \\
\hline \multirow[t]{2}{*}{$\mathrm{TL}(\mathrm{mm})$} & Left & $14.098 \pm 4.855$ & \multirow[t]{2}{*}{3001.000 * } & \multirow[t]{2}{*}{0.550} \\
\hline & Right & $14.607 \pm 7.001$ & & \\
\hline \multirow[t]{2}{*}{$\mathrm{BL}(\mathrm{mm})$} & Left & $23.605 \pm 6.974$ & \multirow[t]{2}{*}{3120.000 * } & \multirow[t]{2}{*}{0.849} \\
\hline & Right & $22.937 \pm 4.119$ & & \\
\hline \multirow[t]{2}{*}{$\mathrm{AD}(\mathrm{mm})$} & Left & $11.863 \pm 2.234$ & \multirow[t]{2}{*}{0.359} & \multirow[t]{2}{*}{0.720} \\
\hline & Right & $11.741 \pm 2.054$ & & \\
\hline
\end{tabular}

Table 4

Gender difference ananlysis of four typical morphological patterns of the aals and the hals

\begin{tabular}{|c|c|c|c|c|c|}
\hline \multirow[t]{2}{*}{ side } & & \multicolumn{2}{|c|}{ gender } & \multirow[t]{2}{*}{ Pearson Chi-square } & \multirow[t]{2}{*}{$p$ value } \\
\hline & & Male & Female & & \\
\hline \multirow[t]{2}{*}{ Type I } & left & 27 & 16 & $1.230(0.821)$ & $0.267(0.365)$ \\
\hline & right & 30 & 28 & & \\
\hline \multirow[t]{2}{*}{ Type II } & left & 7 & 8 & $2.240(1.143)$ & $0.134(0.285)$ \\
\hline & right & 7 & 2 & & \\
\hline \multirow[t]{2}{*}{ Type III } & left & 6 & 6 & $0.434(0.057)$ & $0.510(0.812)$ \\
\hline & right & 7 & 4 & & \\
\hline \multirow[t]{2}{*}{ Type $\rrbracket$} & left & 5 & 2 & $1.167(0.292)$ & $0.280(0.589)$ \\
\hline & right & 3 & 4 & & \\
\hline
\end{tabular}


Table 5

Sulcal parameters' descriptive statistics and gender differences of the aals

\begin{tabular}{|c|c|c|c|c|c|}
\hline \multirow[t]{2}{*}{ Sulcal parameters } & \multirow[t]{2}{*}{ Side } & \multicolumn{2}{|l|}{ Gender } & \multirow[t]{2}{*}{ U or t value } & \multirow[t]{2}{*}{$p$ value } \\
\hline & & Male & Female & & \\
\hline \multirow[t]{2}{*}{$\mathrm{AW}(\mathrm{mm})$} & Left & $3.656 \pm 1.235$ & $3.840 \pm 0.853$ & $542.00 *$ & 0.118 \\
\hline & Right & $3.535 \pm 0.832$ & $3.792 \pm 1.005$ & $541.00 *$ & 0.115 \\
\hline \multirow[t]{2}{*}{$\mathrm{TL}(\mathrm{mm})$} & Left & $20.767 \pm 7.546$ & $18.912 \pm 6.863$ & 1.186 & 0.239 \\
\hline & Right & $21.024 \pm 6.999$ & $20.207 \pm 5.351$ & 0.593 & 0.555 \\
\hline \multirow[t]{2}{*}{$\mathrm{BL}(\mathrm{mm})$} & Left & $23.747 \pm 6.152$ & $21.508 \pm 4.574$ & 1.875 & 0.064 \\
\hline & Right & $26.600 \pm 7.652$ & $23.530 \pm 5.126$ & $698.00 *$ & 0.051 \\
\hline \multirow[t]{2}{*}{$\mathrm{AD}(\mathrm{mm})$} & Left & $12.573 \pm 3.036$ & $10.587 \pm 2.880$ & 3.106 & $0.003^{\star \star}$ \\
\hline & Right & $12.649 \pm 3.013$ & $10.601 \pm 2.528$ & 3.353 & $0.001^{\star *}$ \\
\hline
\end{tabular}

Table 6

Sulcal parameters' descriptive statistics and gender differences of the hals

\begin{tabular}{|c|c|c|c|c|c|}
\hline \multirow[t]{2}{*}{ Sulcal parameters } & \multirow[t]{2}{*}{ Side } & \multicolumn{2}{|l|}{ Gender } & \multirow[t]{2}{*}{ Test statistic } & \multirow[t]{2}{*}{$p$ value } \\
\hline & & Male & Female & & \\
\hline \multirow[t]{2}{*}{$\mathrm{AW}(\mathrm{mm})$} & Left & $3.695 \pm 2.078$ & $3.302 \pm 0.648$ & 940.000 * & 0.867 \\
\hline & Right & $3.687 \pm 1.490$ & $3.518 \pm 0.457$ & 650.000 * & 0.278 \\
\hline \multirow[t]{2}{*}{$\mathrm{TL}(\mathrm{mm})$} & Left & $13.632 \pm 5.368$ & $14.443 \pm 4.462$ & 782.000 * & 0.220 \\
\hline & Right & $12.205 \pm 3.762$ & $16.701 \pm 8.421$ & 424.000 * & $0.008^{* *}$ \\
\hline \multirow[t]{2}{*}{$\mathrm{BL}(\mathrm{mm})$} & Left & $23.125 \pm 6.975$ & $23.960 \pm 7.023$ & 814.000 * & 0.341 \\
\hline & Right & $21.585 \pm 3.346$ & $24.116 \pm 4.400$ & -2.733 & $0.008^{* *}$ \\
\hline \multirow[t]{2}{*}{$\mathrm{AD}(\mathrm{mm})$} & Left & $11.474 \pm 2.218$ & $12.159 \pm 2.223$ & -1.433 & 0.156 \\
\hline & Right & $11.733 \pm 1.948$ & $11.748 \pm 2.168$ & -0.031 & 0.975 \\
\hline
\end{tabular}

Figures 


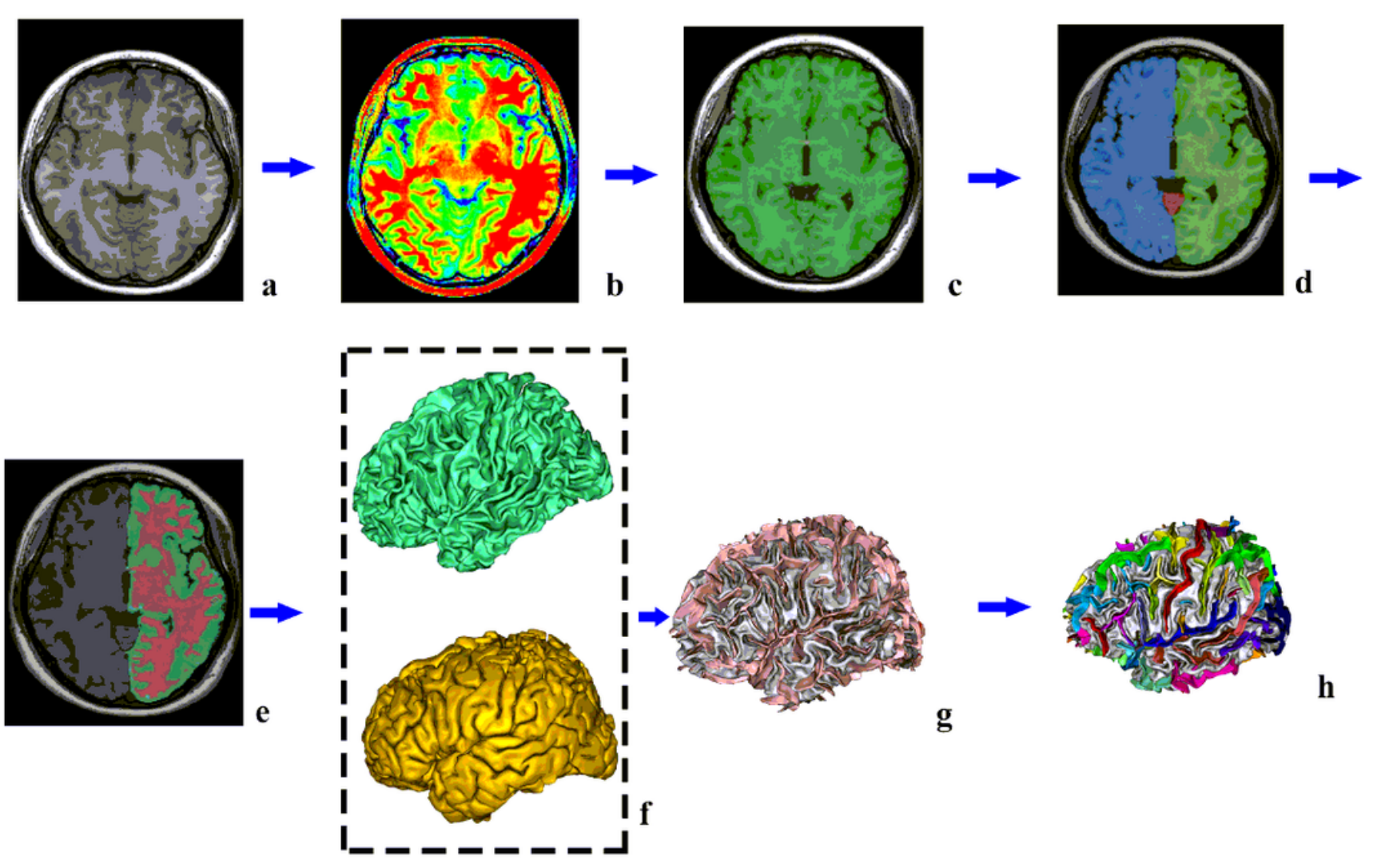

Figure 1

Sulcal extraction and identification pipeline consists of (a) import the T1-weighted MRI into BrainVISA database; (b) bias correction; (c) calculate the mean whole brain mask; (d) meshed the cerebral hemispheres; (e) remove the non-brain tissue and segment the brain tissues into GM, WM and CSF; (f)reconstruction of white/gray matter mesh; (g) sulci recognition and (h) automated labeling of sulci. 

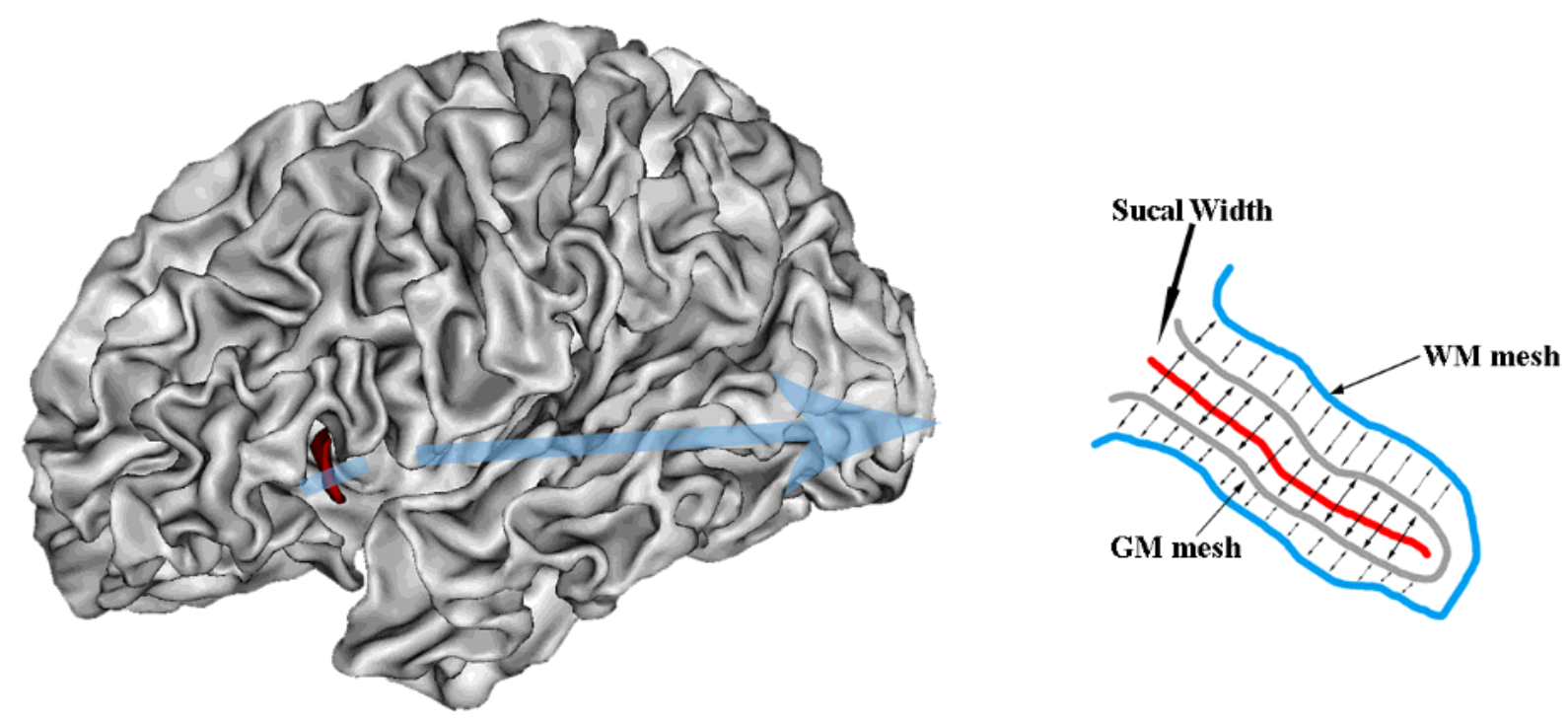

Figure 2

The average sulcal width for an individual sulcal structure is measured as the average width of the intrasulcal space along the normal projections to the sulcal mesh.

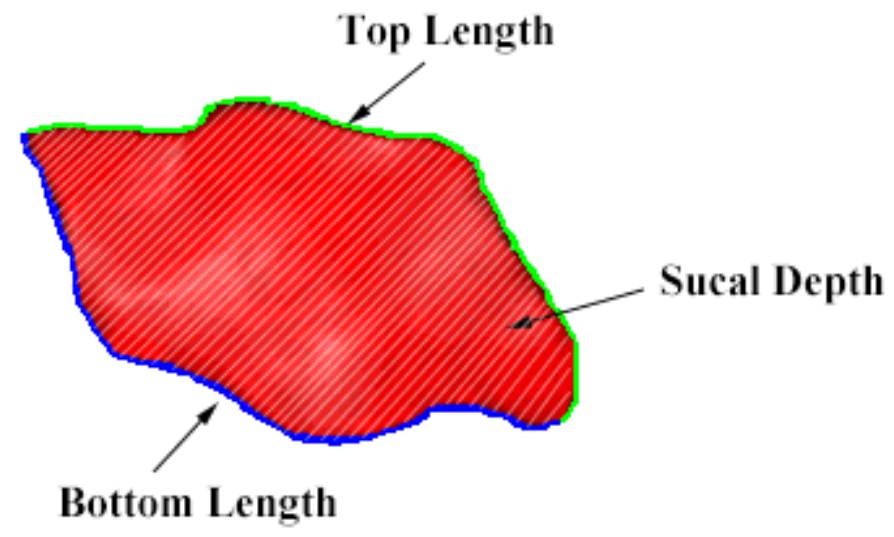




\section{Figure 3}

The average sulcal depth was calculated as the average Euclidean distance between the points along the deepest edge of the sulcal skeleton surface and the nearest points on the outer edge of the sulcal ribbon. The top length was defined as the length of the top edge of the sulcus. The bottom length was defined as the length of the ridge at the base of the sulcus.
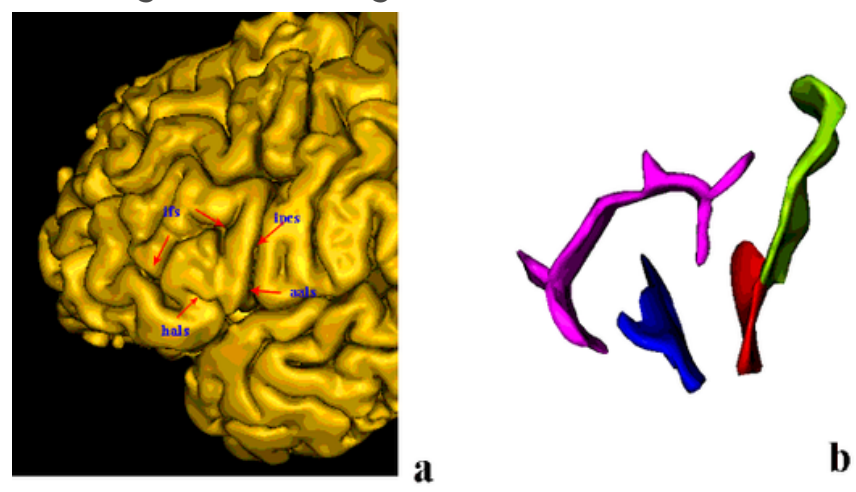

b
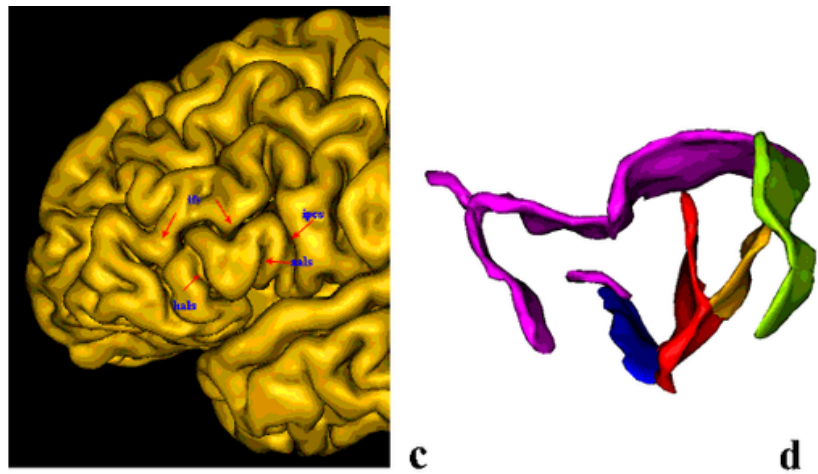

d
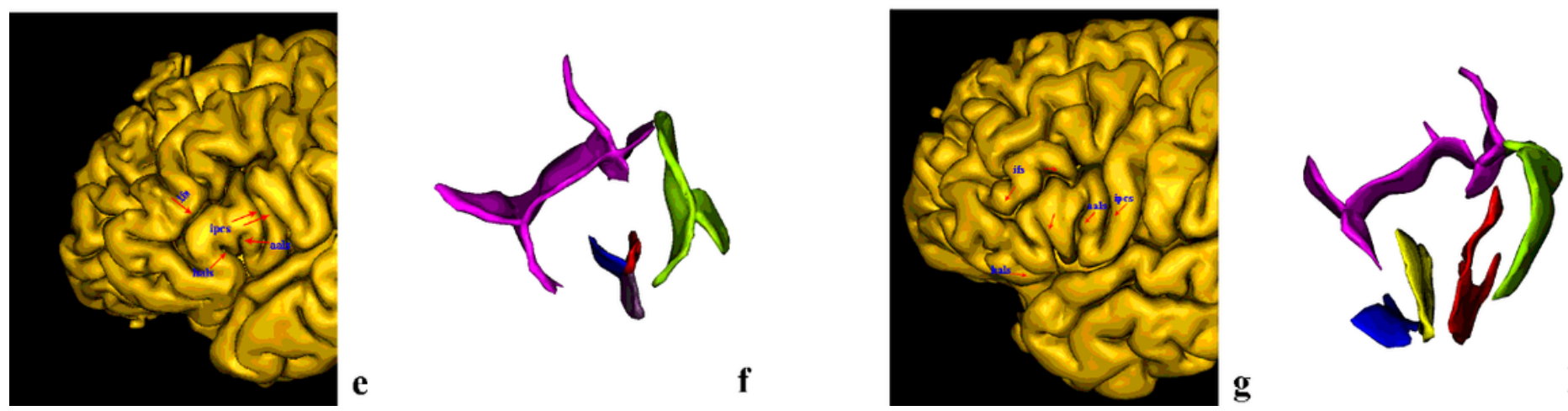

h

Figure 4

Examples of morphological patterns formed by the anterior ascending ramus of the lateral sulcus (aals) and the horizontal ascending ramus of the lateral sulcus (hals). Aals, the red sulci; hals, the blue sulci; the third branch of the lateral sulcus, the pale-yellow sulci; inferior precentral sulcus (iprs), the green sulci, the sulcus diagonalis, the yellow sulci; the inferior frontal sulcus (ifs), the purple sulci. a,b :Type $₫$ was that the aals is clearly separated from the hals, forming the shape of the letter U;c,d: Type $\otimes$ was that the aals and the hals sprang from a common point, forming the shape of the letter $\mathrm{V}$; e, :Type $\otimes$ was that the aals shares a common stem with hals, forming the shape of the letter Y;g,h: Type $\otimes$ was a third anterior ramus of the lateral fissure between the aals and the hals .a,c,e,g: cortical map following sulci reconstruction; b,d,f,h: the pictures of Sulci detail. 

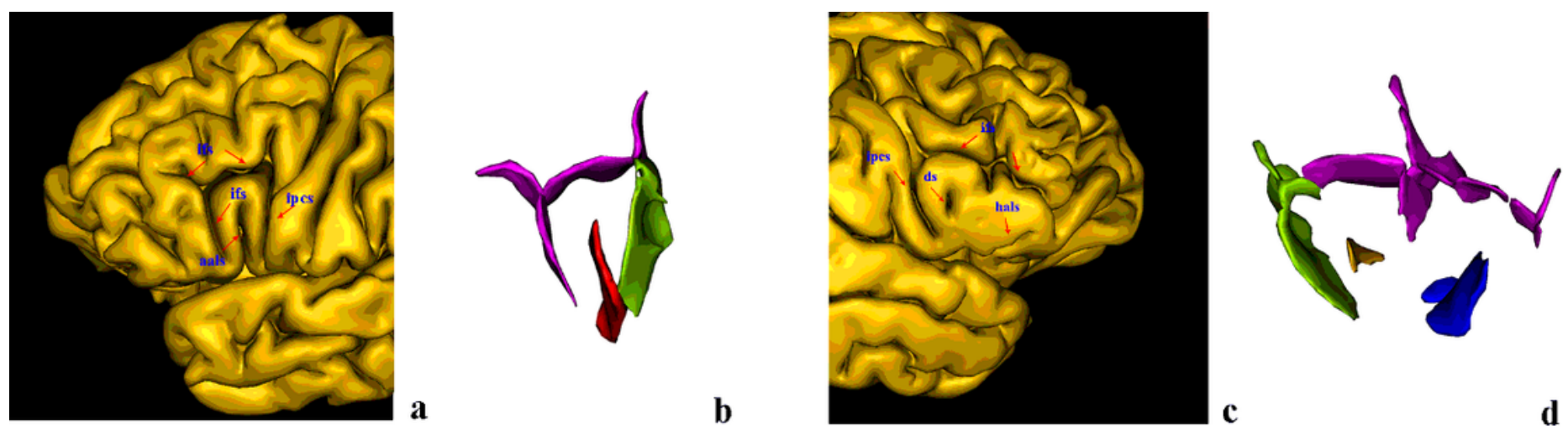

b

d
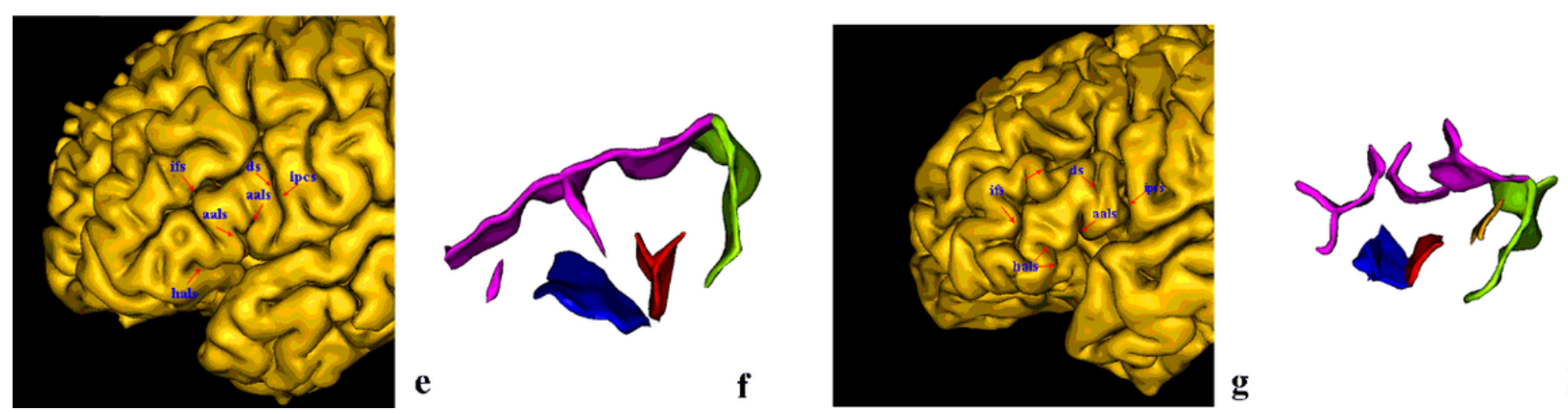

h

Figure 5

Additional examples of morphological patterns formed by the anterior ascending ramus of the lateral sulcus (aals) and the horizontal ascending ramus of the lateral sulcus (hals). $a, b$, There is only one anterior ramus of the lateral sulcus; $c, d$, the horizontal ascending ramus of the lateral sulcus absent; e,f, the aals is bifurcated at its anterior end; $g, h$, the hals is bifurcated at its anterior end. 

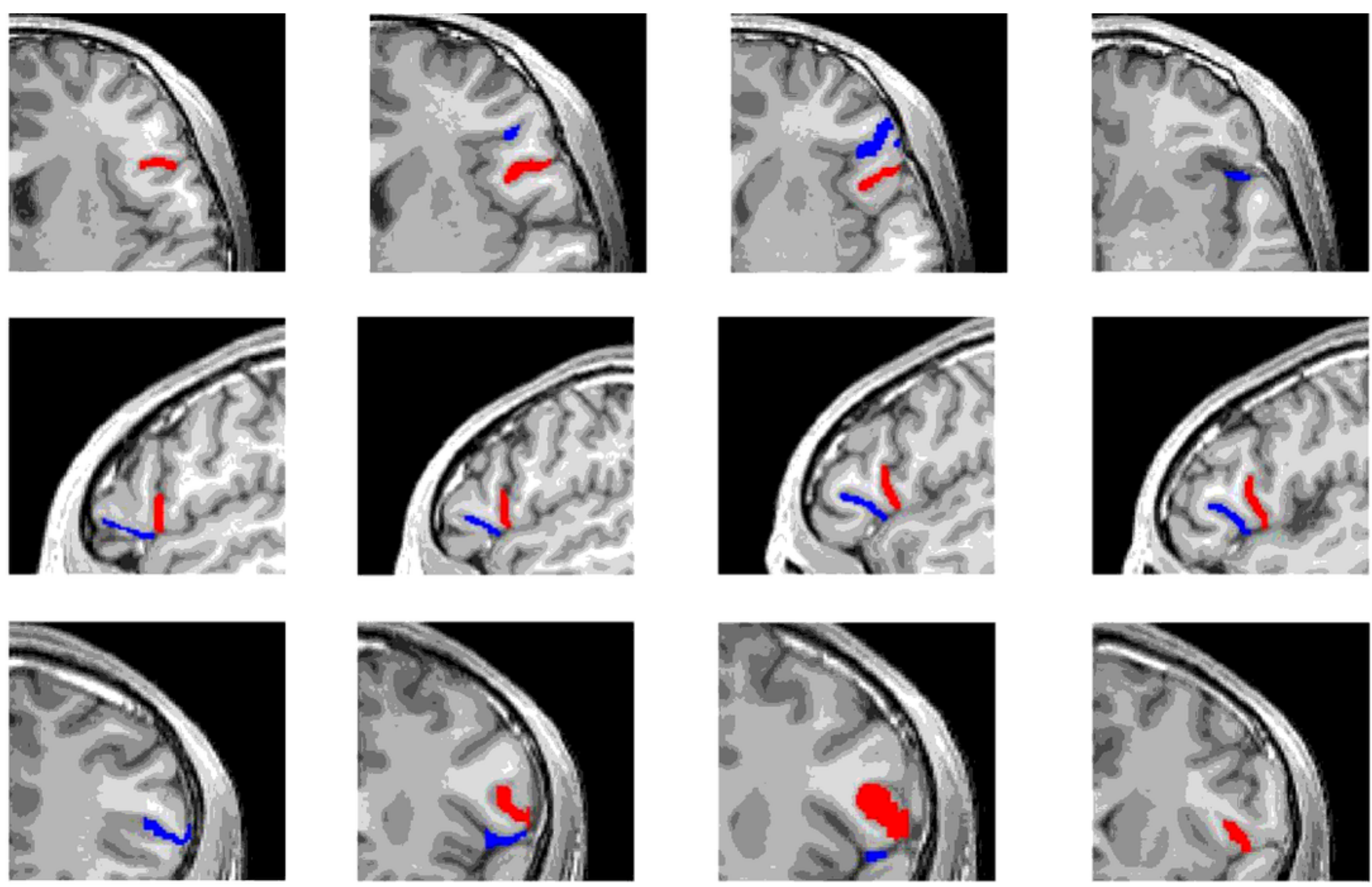

\section{Type I}

Figure 6

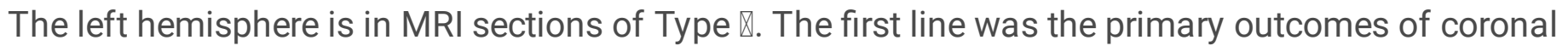
sections, the second line was the primary outcomes of horizontal sections, the third line was the primary outcomes of sagital sections. Red represents the aals, blue represents the hals. 

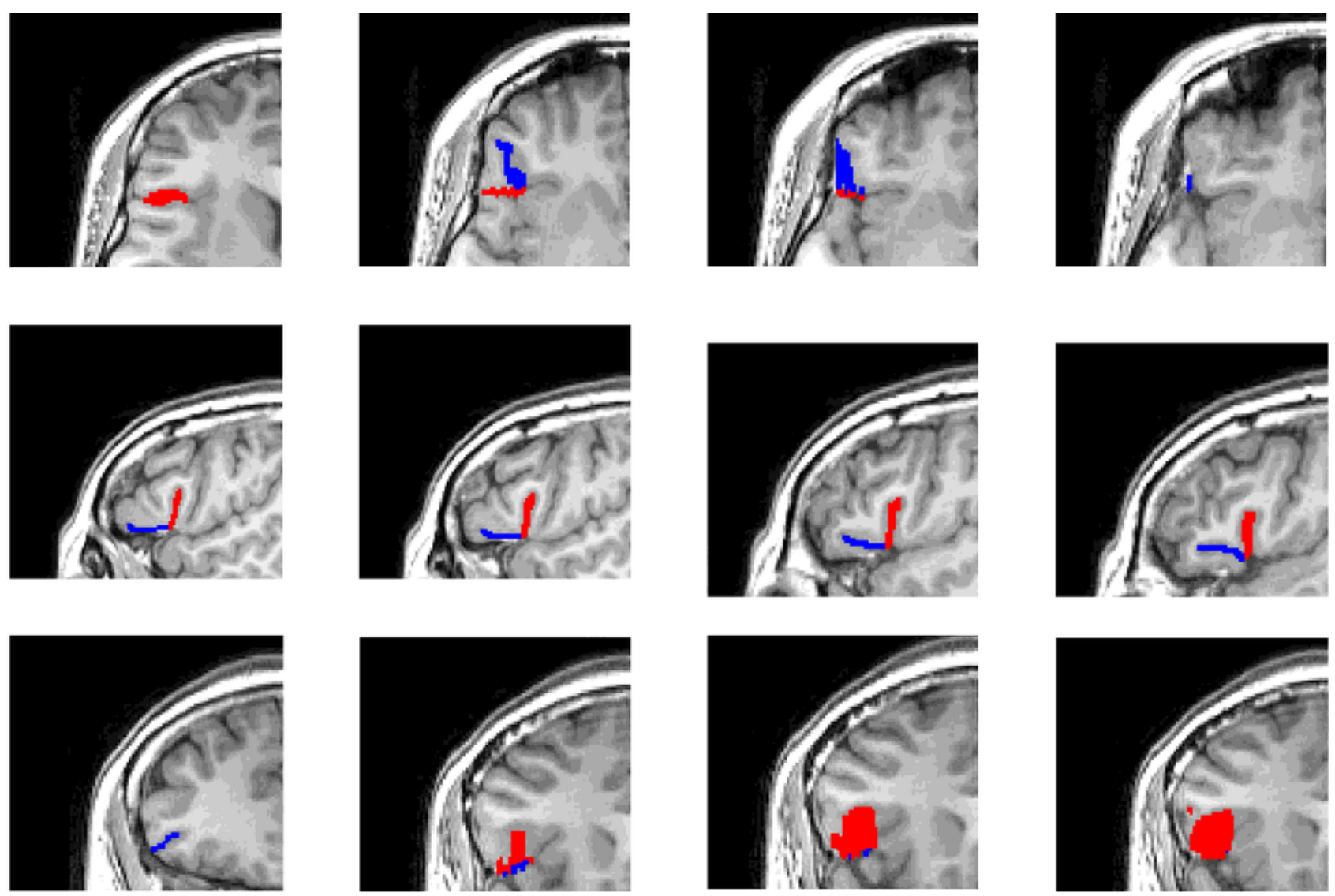

\section{Type II}

\section{Figure 7}

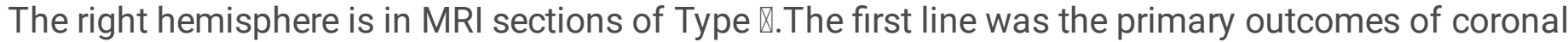
sections, the second line was the primary outcomes of horizontal sections, the third line was the primary outcomes of sagital sections. Red represents the aals, blue represents the hals 

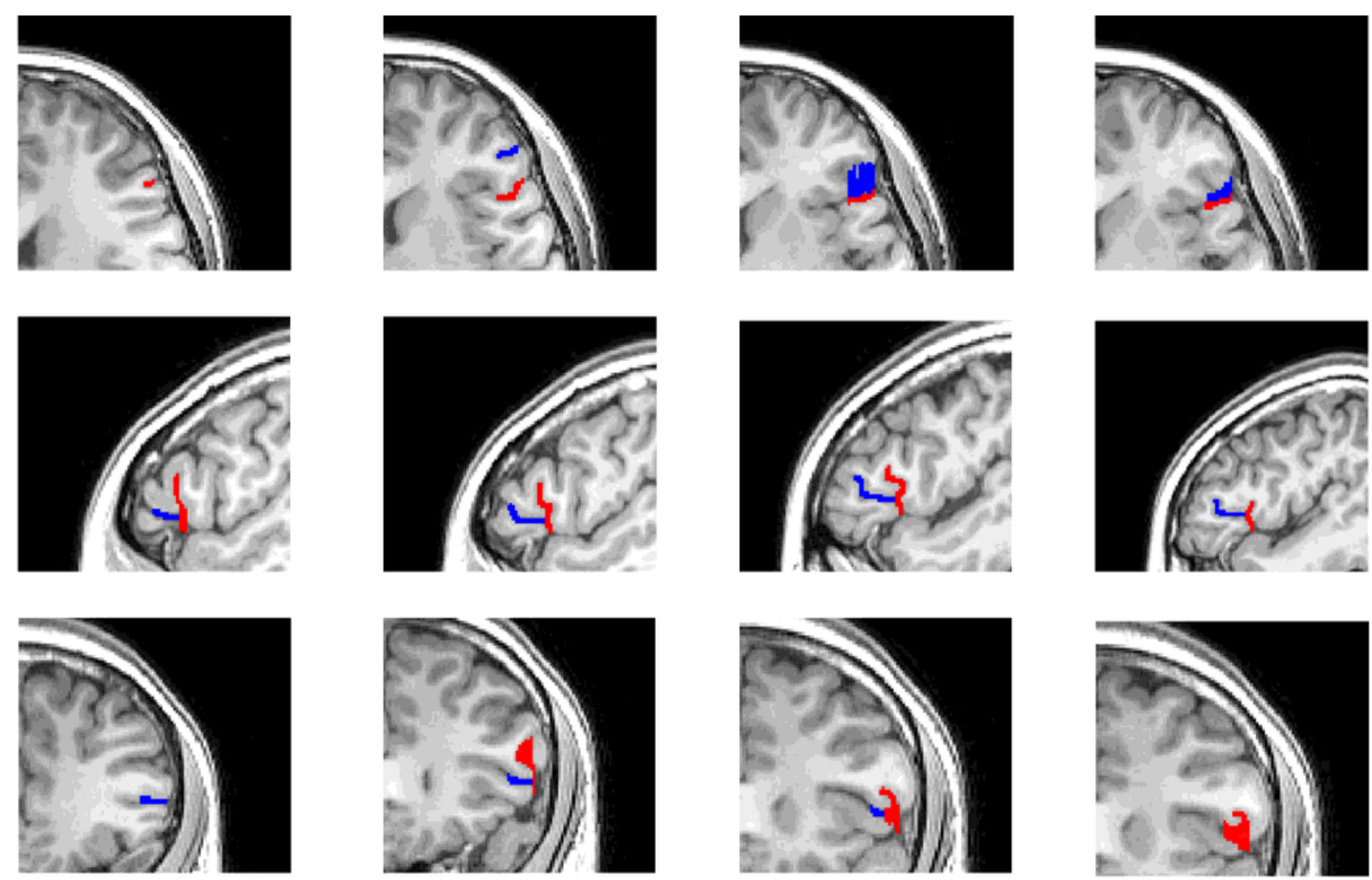

Type III

\section{Figure 8}

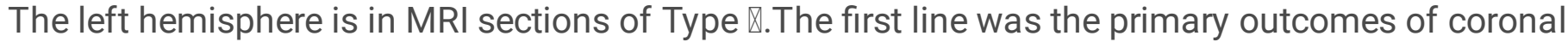
sections, the second line was the primary outcomes of horizontal sections, the third line was the primary outcomes of sagital sections. Red represents the aals, blue represents the hals . 

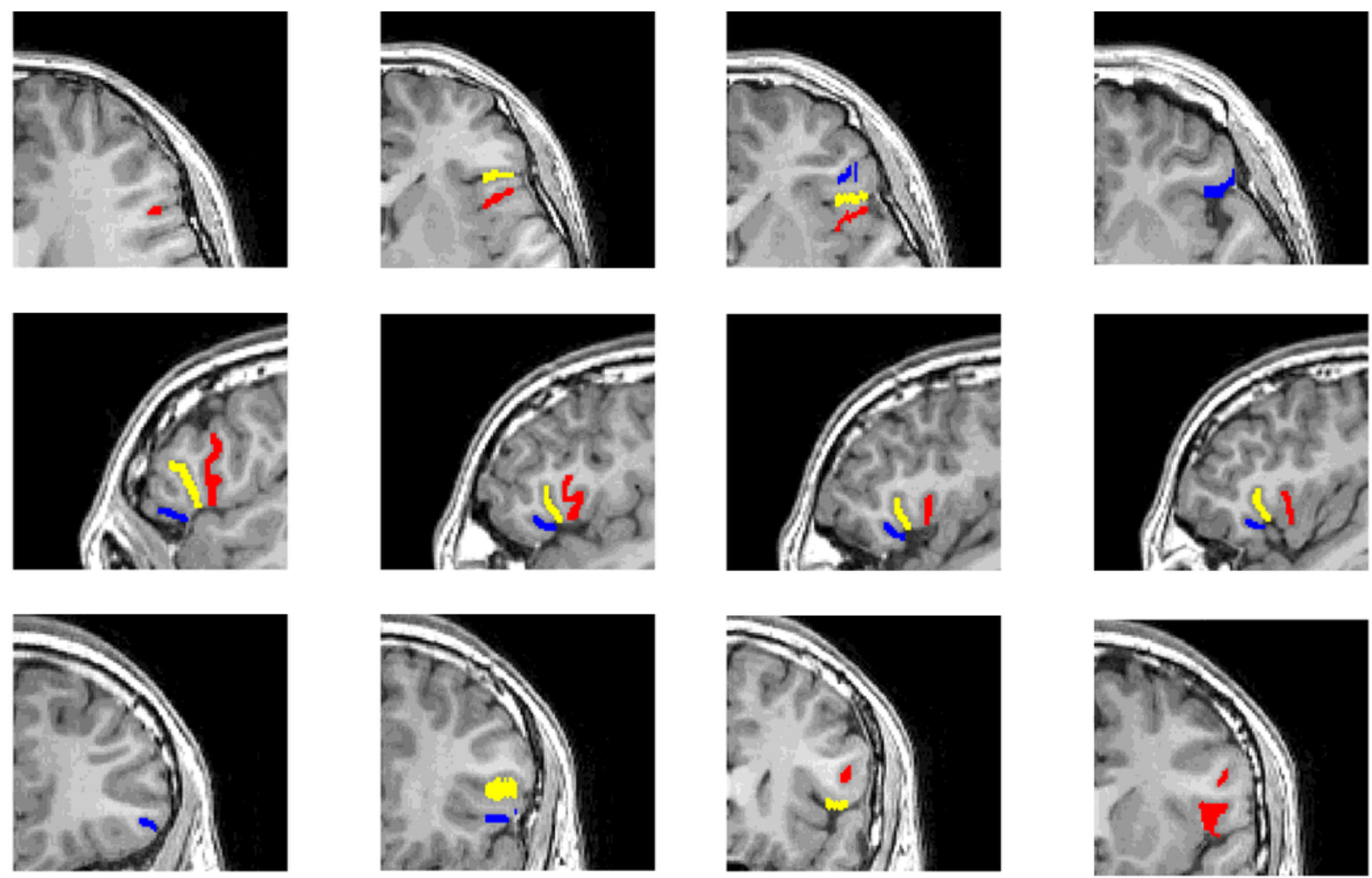

Type IV

\section{Figure 9}

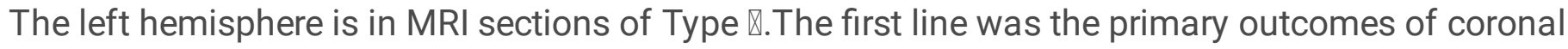
sections, the second line was the primary outcomes of horizontal sections, the third line was the primary outcomes of sagital sections. Red represents the aals, blue represents the hals, yellow represents the third branch of the lateral sulcus. 